In D. Winter \& L. Viney (eds.), Personal Construct Psychotherapy: Advances in Theory, Practice and Research (pp. 136-147). London: Whurr/Wiley. ISBN: 1-86156394-9. (http://eu.wiley.com/WileyCDA/WileyTitle/productCd-1861563949.html)

NOT FOR COMMERCIAL USE. Authors' personal pre-publication copy.

\title{
RESOLUTION OF DILEMMAS BY PERSONAL CONSTRUCT PSYCHOTHERAPY
}

Guillem Feixas

Universitat de Barcelonagfeixas@ub.edu

\section{Luis Ángel Saúl}

UNED-Universidad Nacional de Educación a Distancia, Madrid

Like other constructivist approaches, Personal Construct Theory (PCT) views human activity as a meaning creating process. What human organisms do, is informed by the way they construe events, and in turn assign meaning to those events. Symptoms are a rare, but legitimate part of their activity. They challenge our everyday conceptions regarding human behaviour. From a personal construct perspective, however, they are not an exception to the laws of behaviour, or, an error of nature but activities embedded in a meaning making process.

PCT has elaborated several hypotheses for understanding symptoms as related to the construing process. For example, Fransella (1970), in her study with individuals who stutter, suggested that symptoms could end up being a way of life for the client by becoming a central structure in his/her construct system or identity. In this situation, abandoning the symptoms would involve abandoning a core meaning structure which could be essential for making sense of oneself and the world. Lack of predictability within the construct system would be experienced as anxiety by the person. In terms of Kelly (1995) "Even an obviously invalid part of a construction system may be preferable to the void of anxiety which might be caused by its elimination altogether" (p. 831).

Another type of hypothesis derived from PCT for the understanding of symptoms as related to meaning, focuses on the threat that a change would involve. For some clients, symptom loss, while desirable, may carry negative implications. That is, construing the self with a symptomatic pole of a construct is a way of maintaining their present position in positive poles of other, more central, constructs. This is because the symptomatic construct for which the change is desirable, is linked in their construct system to other constructs for which change is not desirable. For example, Winter $(1988,1989)$ studied clients with social anxiety problems for whom social competence carried negative implications, and the more pronounced these implications, the more negative the outcome in social skills training groups. He suggests that improvement or symptom reduction may confront these clients with guilt (Winter, 1989), which Kelly described as the experience of dislodgement from one's core role (our way of relating to others).

In previous studies (Feixas, Saúl, Avila-Espada, \& Sánchez, 2001; Feixas, Saúl, \& Sánchez, 2000), we described a way of identifying implicative dilemmas from the 
repertory grid which has been implemented in the GRIDCOR (version 4.0) programme (Feixas \& Cornejo, 2002). For that, two different types of construct are differentiated; discrepant and congruent constructs. The former type refers to those constructs for which the subject rates the self now and the ideal self at different ends of the construct poles. For example, on a 7-point Likert scale, the difference would have to be greater than 3 points to meet the criteria for a discrepant construct. A difference of less than 2 would be considered as a congruent construct, i.e. the subject rates the self now and ideal self elements similarly.

Discrepant constructs (e.g. timid vs sociable) indicate areas of dissatisfaction for the individual, areas in which the subject would like to experience substantial change. Often, they represent symptomatic aspects of the person. Conversely, congruent constructs (e.g. modest vs arrogant) reveal areas of satisfaction for the subject. They refer to personal qualities (i.e. modesty) that are not felt to require change, the subject may even be proud of them. The dilemma appears when the desired change in a discrepant construct (becoming sociable) implies an undesired change (i.e. becoming arrogant) in a congruent construct (as measured by a correlation between these two constructs, set up at the minimum level of 20, for clinical practice, or at the level of 0.35 in our research studies). We used the term implicative dilemmas (see figure 1 for a graphical disposition of it) to refer to this type of conflict.

Figure 1. Basic structure of an implicative dilemma derived from repertory grid data.

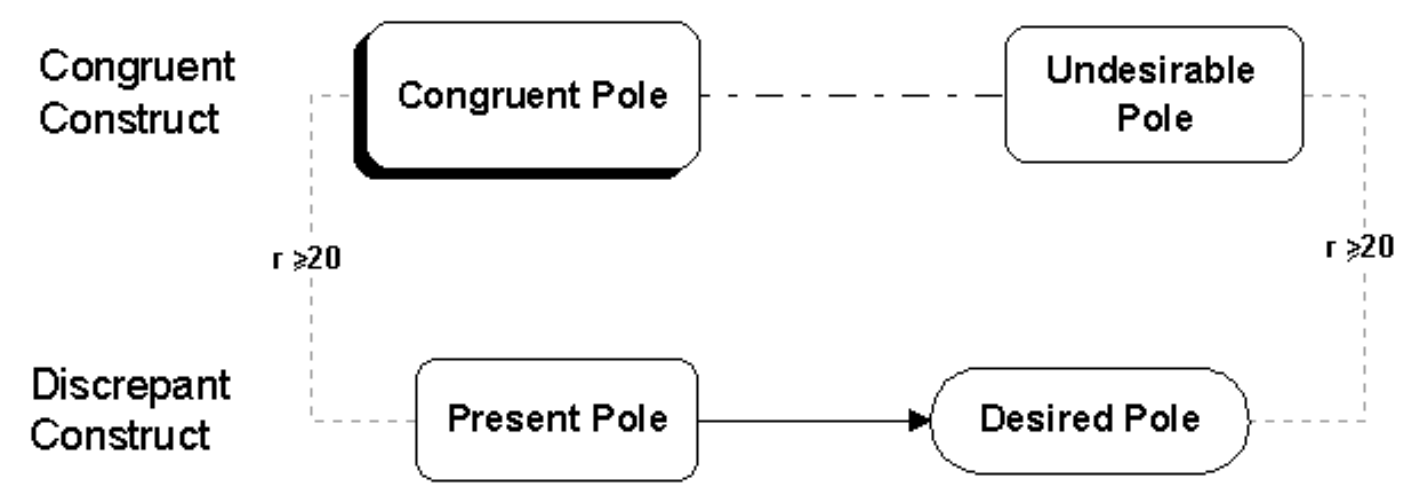

As far as we know, Hinkle (1965,) was the first to employ the term implicative dilemma, however, he was using it in a different sense from ours. For Hinkle, this term referred to a particular form of implication between two constructs (A-B, and X-Y), one that he named "ambiguous":

"A and B imply X, and B implies Y; also A implies $\mathrm{X}$ and $\mathrm{Y}$, and $\mathrm{B}$ implies $\mathrm{X}$ and $\mathrm{Y}$. One subject, for example, when relating desirable-undesirable and realism-idealism, said that realism and idealism both implied desirable and undesirable aspects for him. Conflict theory and double-bind theory relate to these implicative dilemmas" (pp. 18-19, underlined in the original) 
Although, this definition also focuses on the conflictive relationship between two constructs, our definition is different. Our use of the term retains the dilemmatic nature of the phenomena described by Hinkle (1965), but we consider the location of the self now and the ideal self elements as central to the concept. In his definition, Hinkle considered the types of implication between two constructs regardless of where the self and other elements were located. Later, however, he based his laddering and implication methods upon the preferred pole of a construct for a given subject, which is a way of taking into account the ideal self. In light of his method, we think that our use of the term "implicative dilemma", although not exactly as Hinkle defined it, is legitimate within PCT.

Ryle (1979) defined the term implicative dilemma in a way that is more commonly understood nowadays, and the one we use in our present work:

"Dilemmas can be expressed in the form of "either/or" (false dichotomies that restrict the range of choice), or of "if/then" (false assumptions of association that similarly inhibit change). Two common dilemmas could be expressed as follows: 1) "in relationships I am either close to someone and feel smothered, or I am cut off and feel lonely"; (...) 2) "I feel that if I am masculine then I have to be insensitive" (italics in the original).

Another author who expresses even more clearly what we mean by dilemma is Rowe (1970) with the case of a chronically depressed patient embracing a construction whereby her choice was either being depressed and humane or being a destructive and unpleasant person. In general, dilemmas occur when the apparent alternatives available in the construct system are seen both as undesirable. In this vein, Tschudi's (1977) ABC technique is based on this very same idea, that is, that change, although desirable from the viewpoint of a given set of constructs, becomes undesirable from the perspective of another constructs.

\section{Therapeutic practice}

By understanding the symptoms as a part of a meaning-making process, PCT allows both client and therapist to look at distress from an alternative perspective. Often clients present their symptoms in a way which suggests that they do not carry any meaning for them, except for the inconveniences that they cause in their lives. As if the part or aspect of their functioning which is wrong is not related to their sense of identity. Accordingly, mainstream therapists are inclined to consider the problem in terms of its external manifestations, associate them to a clinical diagnosis, and struggle to eliminate the symptoms as quickly as possible. Rather, constructivist approaches direct their efforts in searching for the meanings involved in the problem, that is, to understand the constructions the client erects for him or herself, the problem and how these relate to the problem itself. In particular, the therapy method we propose is addressed to those cases where the problem poses a particular dilemma for the client, from the perspective of his or her construct system.

The first step in our personal construct approach for dealing with dilemmas begins with reframing the problem in terms of the dilemma. Thus, the client's problem is reformulated as a conflict between the desire for change and the difficulty to do that, which results in a blocking of the client's development with considerable suffering and 
symptoms. In our experience, it is useful to show to the client that his or her "impasse" reflects a coherence, an internal logic, rather than being a sign of incompetence, stupidity, or madness, as many clients (and some therapists) believe.

The problem is presented to the client as related to the way of being, or the type of person that the client has chosen to be. Thus, a connection is suggested between the symptoms and the client's self image or personal style. It is suggested also that the "impasse" is a coherent and wise position that the client chooses to uphold, because a change (e.g., becoming social) might involve the abandonment of some of his or her own self-definitions (e.g., modesty) and a shift to their opposite poles (arrogance), which would be undesirable for the client's core structure. In fact, it may be the case that every time explores (in actions or fantasy) the possibility of allocating him or herself in the desired pole (e.g., social) he or she might experience guilt. He or she may begun to construe him or herself outside his o her core role structure (e.g., modesty). Retreat to timidity is the easiest way to alleviate the guilt by returning to his or her "usual" self. In the therapy session, examples of that process are highlighted to help the client realise how this issue constitutes a dilemma in his or her life.

Some clients, after understanding the dilemma pose a question of the type "Would it be possible to become social without having to be arrogant?", to which the therapist replies: "Mmmm.... it seems an interesting question, maybe a project to be implemented. How would you do in the following days to be social without being arrogant?". The later question constitutes in itself a therapy program for the following sessions without pursuing further work on comprehending the dilemma. On the other hand, for some clients the formulation of the dilemma appears as a truth that they already knew but which was never spelled before; for others, as a new construction about their problem, a new perspective that needs to be explored.

Once the client recognises the existence of the dilemma, and the constructs involved, for many clients it is convenient to explore the implications of each of these constructs. For that, we can explore their ascending and descending implications using laddering procedures. Exploring the implications of the dilemma in terms of other, related, constructs allows for a wider understanding of it. It also makes possible to identify new constructs related to the dilemma (other than those obtained during the repertory grid elicitation), and explore new "advantages" for keeping the present position and not changing.

Another central aspect of this work for the elaboration of the dilemma is based on the elements: identifying the prototypical figures that occupy the two positions of the dilemma. On the one hand, the figure(s) who is construed using the undesired pole in the discrepant construct but the preferred pole in the congruent construct (e.g., timid and modest), and on the other hand, the one(s) who is construed according the desired pole in the discrepant construct but under the undesirable pole of the congruent construct (e.g., social and arrogant). Thus, the dilemma can be phrased in terms of the types of person that each prototypical figures represent.

In one of our cases ${ }^{1}$, Laia, a 24 -year old girl presenting with problems of insecurity and lack of confidence in engaging in master level courses, she recalled that in her family it was commonly assumed that his brother Josep was bright in school while she was "a

\footnotetext{
${ }^{1}$ The therapist for this case was Guillem Feixas. Client names used in this chapter have been changed to protect their confidentiality.
} 
good person". Her family (including herself) did not expect her to have good grades at school. Instead, they expected her to take care of her younger sister while their mother was a $t$ work, or even joining the father for an excursion day during the weekend. For Laia, achieving good success in the University was equated to resembling her brother Josep who was also described by her as an "uncaring" and "selfish" kind of person.

The exploration of the dilemma stimulated the client memories and narratives about the dilemma and its prototypical figures, which is a common process in other cases as well. Then, when these figures are identified the therapist asks "Do you think that if you would become successful in your studies you would also become similar to your brother as a person?". Laia replies that that is probably so although never thought of it in that way. At this point, the dilemma can be phrased in terms of a change that would involve a change in the type of person one has always been to become a different type of person, one which is not preferred since the prototypical figure that represents it (e.g., the brother) is disliked in many senses.

One interesting development that might follow, is finding out whether the client can think of figures situated both in the congruent and the desired poles of the dilemma (e.g., people who is social and also modest). This exploration may lead to realise that that path has already been walked, and to discuss whether that is a viable option for the client him or herself.

All this work with the dilemma is made in a way that underlines the coherence of the symptom by clarifying its function of validating the client's values and sense of identity. Tschudi's (1977) ABC technique can be of great help in this process because in it the disadvantages of change are also made evident. Besides, it may serve to clarify the symptom's function, or the aspect to change in the actual context of its construction. With that, new constructs related to the dilemma, unforeseen advantages, or previously undetected constructs may also appear. These conversational procedures allow us to go beyond the construct universe delimited by the repertory grid.

Once the dilemma is a accepted as a new construction about the problem by the client, and its implications have been explored, controlled elaboration can be a useful option. Suggested by Kelly (1955), it can be defined as the attempt to make consistent and communicable one part of the client's construct system to make it possible to contrast its validity. To use controlled elaboration to work with dilemmas we suggest to begin by focussing the conversation on the dilemma theme, accompanying the client on the experience cycle, phase by phase (e.g., noticing which constructs are being validated or invalidated, etc.). To weigh up each construct of the dilemma with the client, exploring the conditions in which is being validated or invalidated, working with the ascending and descending implications of those constructs. This process may help the client to elaborate his/her thoughts and feelings related to the dilemma with more care and precision than in the normal flow of life, that is, to promote the observer role, the client's self-observation (Guidano, 1991).

Although in many cases it is not necessary to promote change, in some it might be useful to explore the origins (the primary focus of convenience) of the dilemma in order to erect an historical reconstruction of it. For this client and therapist can search for past episodes which exemplify the dilemma across the client's life. This process can be exemplified by the case of Laia (see above) whose memories of the family's construction (Procter, 1981) of her as a "good person" and her brother Josep as "bright" 
refer to the time of her being 8 or 9 years old. Often, this exploration of past events, many of them back in infancy, provoke intense emotional expressions.

This historical perspective on the dilemma permits the client to contemplate him or herself from a different position that both facilitates understanding of his or her personal evolution and allows to envision new alternatives. At this point, it is useful to acknowledge that the dilemma was structured in that way according to a given historical, emotional, and relational context. However, in the present, things can be seen differently (Kelly's, 1955, “time binding”).

At different moments of this process, generation of alternatives to explore nondilemmatic solutions are promoted. In sum, all this process is aimed at creating a live without the dilemma. For that, it is convenient for the client to be aware of the existence of possible alternatives to dilemma construction and theses alternatives are not better 0 worse than others. They are simply other possible alternatives. As with the brain storming technique, it is a good idea not to evaluate these new alternatives too quickly. Rather, they can be explored using imagination or role playing.

Finally, an optional phase in the dilemma resolution work is engaging the client in fixed role of the solved dilemma, an adaptation of Kelly's original technique (1955). The client is asked to represent a role, designed by the therapist, which includes among others characteristics, the congruent and desired poles of the dilemma are present. So in this role the dilemma is not present. With this, it is intended to provide the client with a lived experience, in his or her habitual environment, of him or herself living without the dilemma.

\section{THE CASE OF TERESA}

This patient is in the final year of her degree on chemical sciences. She was treated by the psychological care services of the University of Salamanca. At the initial assessment she displayed somatization, depressive symptoms, and a high level of interpersonal sensitivity according to the scales of SCL-90-R (Derogatis, 1977). Although Teresa proves to be an excellent student, she reveals serious doubts about her self worth. She cries frequently, and has great difficulty in meeting others, even though she has a boyfriend who is extremely supportive. The relationship between her and her parents is very strained, she describes her mother as a very dependent person who puts a great deal of pressure on her. Her parents live $80 \mathrm{Km}$ from the city. At the moment of the consultation, Teresa lives with her brother, but the two of them have not been on speaking terms for three months.

The first time that I interviewed her ${ }^{2}$, she explained to me that in a few weeks time she would be travelling $600 \mathrm{~km}$ from home to work into a firm that would allow her to gain work experience in a field related to her studies. Teresa displays great insecurities regarding her departure, she questions whether or not she should go, but she is aware that it is necessary for her to go ahead with her plans. We would have two support sessions before her departure where I would focus on preparing the patient to realise the benefits of this upcoming experience.

\footnotetext{
${ }^{2}$ The therapist for this case is Luis Ángel Saúl.
} 
After analysing the client's grid we identified two implicative dilemmas related to her depressive symptoms (see figure 2). 
Figure 2. Implicative Dilemmas identified in the initial grid of Teresa.

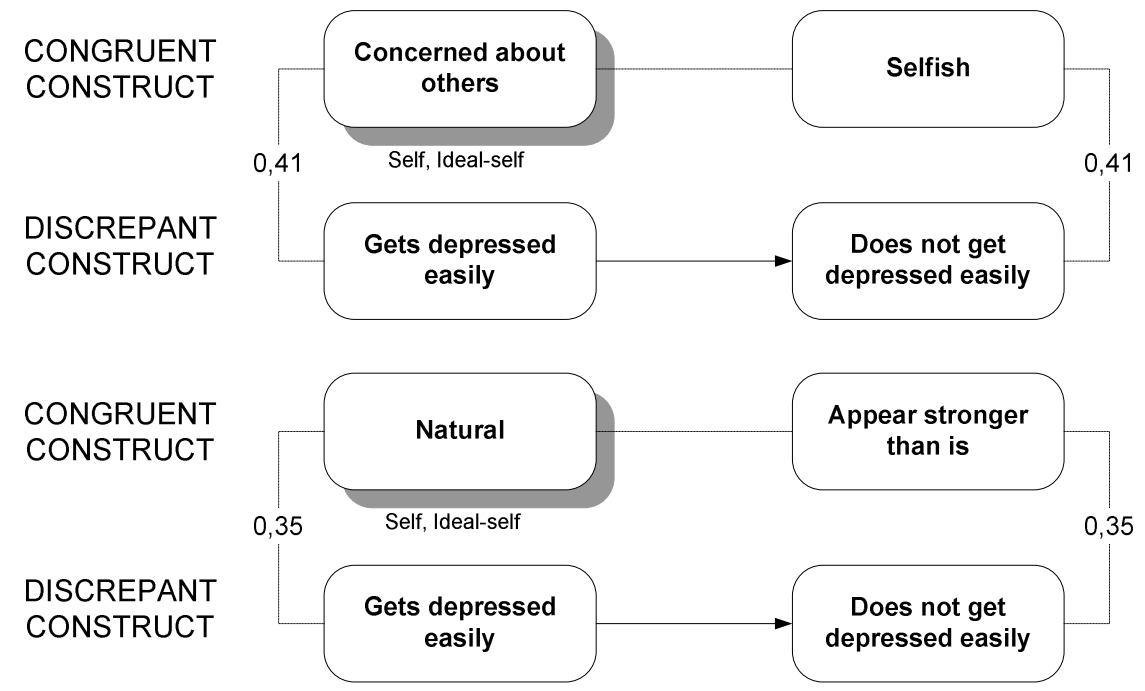

The patient associates the construct pole "does not get depressed easily" with two construct poles that she considers opposite to her self-definition:

1) To be "selfish" (vs. concerned about others)

2) 2) To be the kind of person that "pretends to be stronger than one is" (vs. natural).

The aim of therapy was to sever these associations, as at present, they were preventing the client from forming alternative definitions of her self i.e. as a person who does not get depressed easily. As a consequence of implicative dilemma resolution, the client would be alleviated of her depressive symptoms.

According to our therapeutic hypothesis, we should help the patient to elaborate in alternative ways the implications of her nuclear constructs and to facilitate a wider perspective in which to view herself. Loosening the implications of her nuclear constructs would help Teresa to see herself as a person who is natural, concerned about others, (the opposite of a "selfish" person and one who pretends "to be stronger than one is") whilst at the same time "does not get depressed easily".

The period of time between the first and the last grid was only four months. The therapy had to end just before the academic holidays, so we didn't have much time to work. However, the patient began to show signs of elaboration (expansion) of some of her nuclear constructs. She started to appreciate that "concern about others" also implies concern about oneself. Thus, the construct became more permeable so to include the self among the range of its elements. Probably as a consequence of this reconstruction, the client's psychological well being was enhanced and therefore her depression reduced as denoted by the assessment at the end of therapy.

We can observe the changes in Teresa's construing by looking at the correlations among the constructs forming the dilemma at the end of therapy (figure 3 ) and comparing them to those of initial assessment (figure 2). 
Figure 3. The implicative of dilemmas of Teresa's post-therapy grid.

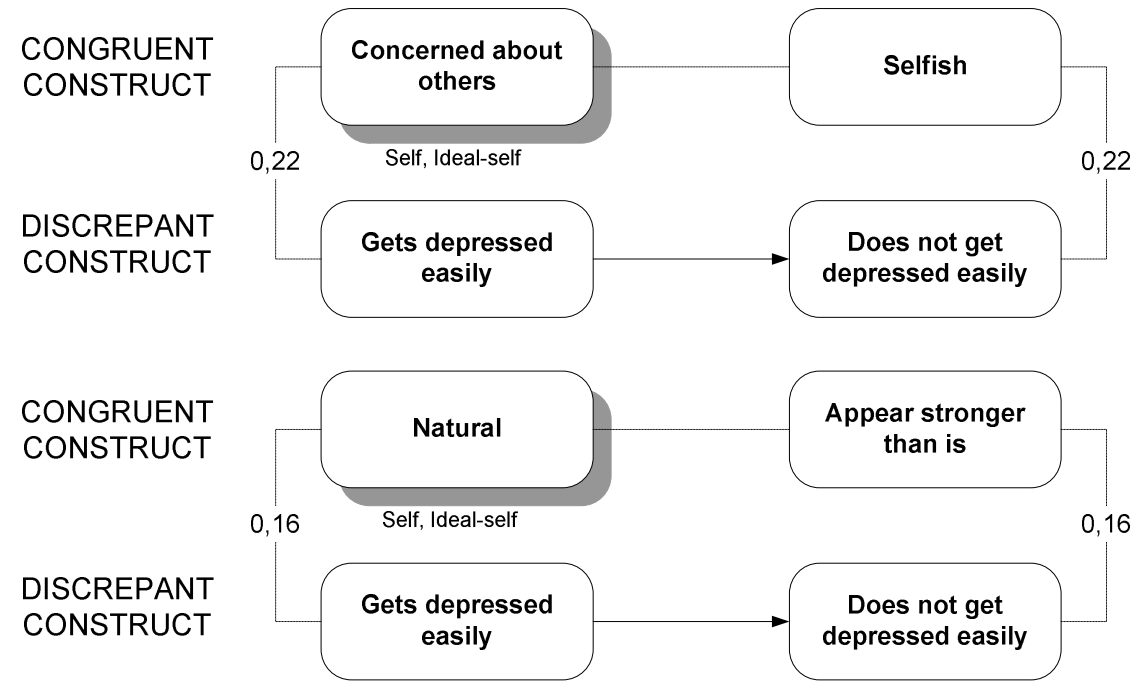

As it can be seen, a reduction has been achieved in the degree of association between those constructs which formed dilemmas. Although these correlations are still positive after therapy the reduction of their intensity is noticeable. In addition, it was found that reduction in the intensity of the dilemmas was accompanied by symptom reduction. Although variations in the SCL-90-R scales were not substantial, her BDI score changed from 26 (at the start of therapy) to 9 (at the end of therapy).

\section{Research}

A multicentre research project was launched in 1999 to investigate the role of dilemmas in different mental and physical health problems, and also to device and implement therapeutic methods focussed in resolving those dilemmas (see more details in Feixas, Saul \& Sánchez, 2000; and in Internet: www.usal.es/tcp). Currently, various Universities and clinical centres mainly from Spain but also from the United Kingdom, Portugal, Italy and South America, are involved, at different levels, in this project.

A preliminary data report (Feixas \& Saul, 2003) informs that dilemmas can be identified in grids of one third (34\%) of a non clinical sample of 321 subjects recruited by psychology students after some training in grid administration and analysis. In a clinical sample of 286 psychotherapy clients presenting with a wide variety of clinical problems (excluding psychosis), dilemmas appear in more than one half $(52,4 \%)$ of the sample. This difference proved to be significant using a chi-squared test.

To further investigate the number of dilemmas appearing in each sample (amongst those subjects who presented at least one), we computed the Percentage of Implicative Dilemmas (PID) measure ${ }^{3}$. The clinical sample $(4,37 \%)$ doubled the non-clinical sample $(2,11 \%)$, a significant difference.

\footnotetext{
${ }^{3}$ Although the number of dilemmas in a given grid would seem an obvious measure, we have found, in a pilot study, that the amount of dilemmas may increase with grid size. Therefore, as grid size is not standardized, grids cannot be reliably compared.
} 
This first exploratory result indicates that

a) The presence of dilemmas as captured by repertory grids is a usual, natural, situation in humans at least to some degree.

b) Subjects consulting for clinical problems are more likely to present dilemmas than subjects who don't.

c) Grids of subjects presenting with psychological symptoms yield a greater number of dilemmas.

Points (b) and (c) suggest that dilemmas are related to psychological distress but point (a) cautions us against considering dilemmas necessarily as a pathological sign. Altogether, our research seems to suggest that dilemmas are part of life but when not addressed or excessive in number (and maybe in intensity) can be associated with suffering and pathology. This can be seen as an argument in favour of the idea that there is not a discrete line distinguishing between "normal" and "pathological" subjects. Maybe we, as humans, develop symptoms (among many other reasons) when the dilemmas we face are excessive, "in over our heads" (Kegan, 1994).

With respect to therapy and its influence in resolving dilemmas, Feixas and Saul's (2003) preliminary report informs of another study with 87 clinical patients, this including a re-analysis of 46 neurotic clients which were part of the sample used by Watson (1998). We examined the presence or absence of implicative dilemmas before and after therapy. From the data, it can be observed that subjects who do not present with implicative dilemmas at the start of therapy are unlikely to exhibit them when therapy ends, only $7.9 \%$ of the patients who did not exhibit implicative dilemmas at the start of therapy did so at the end. More than 2/3 (69.4\%) of the sample who presented with implicative dilemmas at the start of therapy did not present with implicative dilemmas at the end. Finally, less than one third (30.6\%) of subjects who presented with implicative dilemmas at the start of therapy, presented with implicative dilemmas at the end (less than $1 / 3$ of the sample). This data suggest that psychological therapy, even when it is not specifically addressed to resolve previously identified dilemmas, produces a statistically significant reduction in the number of implicative dilemmas of the patients $(\mathrm{p}<0.001)$.

$\frac{d}{(n ! / 2 \cdot[(n-2) !])} \cdot 100$

$\mathrm{d}=$ number of dilemmas

$\mathrm{n}=$ number of constructs in the grid

A method was devised to counteract for this difficulty which takes account of the number of constructs in the grid. The number of possible pairs of constructs was calculated and used as the denominator in the formula. The result of this equation is multiplied by 100 , in order to establish the percentage. 
Overall, we find that the percentage of patients who present with implicative dilemmas after the therapeutic process is $20.7 \%$. In comparison with $34 \%$ found in the nonclinical sample mentioned above this is a lower profile of dilemmas for clients who completed a psychotherapy process. This datum suggests that therapy decreases the number of implicative dilemmas to a level below that of the general population. So, psychotherapy does not merely return subjects to a normal level of conflict within their construct system but actually serves to enhance or facilitate their construing to a level more resolved and dilemma free than average.

Obviously, more research is needed for exploring differences among psychotherapy approaches and their influence in decreasing the number of dilemmas, and, more important, for assessing whether a brief therapy protocol focussed in resolving previously identified dilemmas produces good outcomes both in terms of symptom reduction and dilemma's resolution.

\section{CONCLUSIONS}

Conceptualizing the problem presented by the client in terms of a dilemma, is way of understanding it in terms of a meaning making process consistent with a constructivist perspective. Thus, by inhabiting in the symptom pole the subject is validating other core constructs about her or his identity which are associated with it. Change to the opposite pole, the desired pole, would also imply abandoning part of his or her identity, which would involve a central change in the construct system of the client.

Implicative dilemmas can be identified using the Repertory Grid Technique, and assessed for each subject's grid in terms of their presence (or not), and also the proportion of dilemmas found.

The results so far obtained from the Multicentre Dilemma Project indicate that one third of a non-clinical sample present with implicative dilemmas, which suggests that dilemmas (even those detected using repertory grids) are part of tensions of "normal" life. However, they are more common (and more numerous) for subjects asking for help in psychotherapy services. Further data with therapy clients show that psychological therapy, even when it is not specifically addressed to resolve previously identified dilemmas, produces a statistically significant reduction in the number of implicative dilemmas of the patients.

These results suggest that more attention should be paid to implicative dilemmas in the therapy process. Personal construct therapy provides with a number of useful clinical techniques (reframing, laddering, ABC, controlled elaboration, historical reconstruction, generation of alternatives, fixed role, etc.) that can be adapted to work with these dilemmas and dissolve them. In this way, the person can feel that change can be consistent with his or her identity, and, thus, be more easily attainable.

\section{References}

Derogatis, L. R. (1977). SCL-90-R: Administration, Scoring and Procedures Manual I for the Revised Version of the SCL-90. Baltimore, MD: John Hopkins University Press. 
Feixas, G. \& Saúl, L. A. (2003). Dilemma project internal report (Database, April, 2003). Unpublished document.

Feixas, G., Saúl, L.A., Avila-Espada, A. y Sánchez, V. (2001). Implicaciones terapéuticas de los conflictos cognitivos. Revista Argentina de Clínica Psicológica, vol. X (1), 5-13.

Feixas, G., Saúl, L. A., y Sánchez, V. (2000). Detection and analysis of implicative dilemmas: Implications for the therapy process. En Joern W. Scheer (ed.), The Person in Society Challenges to a Constructivist Theory (págs. 391-399). Giessen: Psychosozial-Verlag.

Fransella, F. (1970). Stuttering not a symptom but a way of life. British Journal of Communication Disorders, 5, 22-29.

Hinkle, D. N. (1965). The change of personal constructs from a view-point of a theory of construct. Unpublished $\mathrm{PhD}$ Thesis. The Ohio State University.

Kegan, R. (1994). In over our heads: The mental demands of modern life. Cambridge, MA: Harvard University Press.

Kelly, G. (1955). The psychology of personal constructs (2 vols.). New York: Norton (reprinted by Routledge, London, 1991).

Procter, H. G. (1981). Family construct psychology an approach to understanding and treating families. In S. Walrond-Skinner (Ed.), Developments in Family Therapy . London: Routledge \& Kegan Paul.

Ryle, A. (1979). The focus in the brief interpretative psychotherapy: Dilemmas, traps and snags as target problems. British Journal of Psychiatry, 134, 46-54.

Tschudi, F. (1977). Loaded and honest questions a construct theory view of symptoms and therapy. In D. Bannister (Ed.), New Perspectives in Personal Construct Theory . London: Academic Press.

Watson, S. B. (1998) A process and outcome study of personal construct, cognitive and psychodynamic therapies in a NHS Setting. Unpublished PhD. Tesis, University of Hertfordshire.

Winter, D. A. (1988). Constructions in social skills training. In F. Fransella, \& L. Thomas (Eds.), Experimenting with Personal Construct Psychology (pp. 342-356). Londres Routledge \& Kagan Paul.

Winter, D. A. (1989). Resistance to therapy: Stubborn opposition or constructive choice? Paper presented at 3rd European Conference on Psychotherapy Research, Bern. 